\title{
Unilateral congenital nasolacrimal duct obstruction and amblyopia risk factors
}

This article was published in the following Dove Press journal:

Clinical Ophthalmology

\author{
Akshay Badakere \\ Tabita Naomi Veeravalli \\ Sadiya Iram \\ Milind N Naik \\ Mohammad Javed Ali \\ Govindram Seksaria Institute of \\ Dacryology, L.V. Prasad Eye Institute, \\ Hyderabad, India
}

Introduction: This study aimed to investigate the prevalence of amblyopia risk factors in patients with unilateral congenital nasolacrimal duct obstruction (CNLDO).

Patients and methods: A retrospective interventional case series was performed on all consecutive patients of unilateral CNLDO who underwent probing over a 6-month period in 2017. All patients underwent a complete ocular examination, retinoscopy, axial length measurements and keratometry. Risk factors for amblyopia were noted based on the American Association for Pediatric Ophthalmology and Strabismus guidelines. The fellow eye of the patients with CNLDO was taken as an internal control. Statistical analysis was performed using Stata version 13.0 statistical software. A $p$-value of $\leq 0.05$ was considered statistically significant.

Results: One hundred eyes of 50 patients were studied. The median age at presentation was 36 months without any gender predisposition (M: 26, F: 24). All patients presented with symptoms of epiphora. Seven (14\%) of the patients were noted to have amblyopia risk factors: five $(10 \%)$ were secondary to refractive errors and two $(4 \%)$ had congenital cataracts. The anisometropia noted in the five patients showed the worse eye to be the one with CNLDO in all the cases. The common refractive error noted was a compound hyperopic astigmatism in three eyes followed by mixed astigmatism and simple hyperopia in one eye each.

Conclusion: The prevalence of amblyopia risk factors in children with unilateral CNLDO is marginally higher than that reported in general population. Hence, a thorough evaluation should be carried out to detect amblyopia risk factors and for their prompt management.

Keywords: congenital, amblyopia, CNLDO, lacrimal

\section{Introduction}

Congenital nasolacrimal duct obstruction (CNLDO) is one of the common causes of pediatric epiphora with incidence of symptoms ranging from $1 \%$ to $30 \%{ }^{1,2}$ The natural history of disease demonstrates high rate of spontaneous resolution by the age of 1 year. $^{3}$ The standard of care for nonresolving cases is irrigation and probing with or without intubation. Amblyopia is known to affect $1.6 \%-3.6 \%$ of the general population. ${ }^{4,5}$ Many risk factors are known to predispose to amblyopia and include refractive errors, strabismus and media opacities like cataract and corneal scars. The association of CNLDO with refractive errors and amblyopia risk factors is controversial with reports in the literature supporting as well as refuting the association. ${ }^{5-13}$ The present study analyzed amblyogenic risk factors exclusively in patients with unilateral CNLDO in comparison with their fellow eye, which served as an internal control.

\section{Patients and methods}

Approval for the study was obtained from the institutional review board of L.V. Prasad Eye Institute. A retrospective interventional case series was performed on all 
consecutive patients of unilateral CNLDO who underwent probing over a 6-month period from April to September 2017. Written informed consent was obtained from their parents for review of their medical records. Preoperatively, all patients underwent examination of visual acuity, and assessment for any ptosis or manifest strabismus. After obtaining consent of the parents, the patients were examined under anesthesia before irrigation and probing, which included an anterior and a posterior segment examination under complete dilatation, cycloplegic refraction, axial length measurements and keratometry. Risk factors for amblyopia were noted based on the American Association for Pediatric Ophthalmology and Strabismus (AAPOS) guidelines. ${ }^{14}$ The following were considered as risk factors: anisometropia greater than $1.5 \mathrm{D}$, any manifest strabismus, hyperopia greater than $3.5 \mathrm{D}$ in any meridian, myopia magnitude greater than $3.0 \mathrm{D}$ in any meridian, any media opacity greater than $1 \mathrm{~mm}$ in size, astigmatism greater than $1.5 \mathrm{D}$ at $90^{\circ}$ or $180^{\circ}$ or greater than 1.0 D in oblique axis or ptosis $>1 \mathrm{~mm}$ margin reflex distance. The fellow eye of the patients with CNLDO served as an internal control for comparison.

Statistical analysis predominantly consisted of descriptive analysis. Normality of the data was analyzed using ShapiroWilk test. Descriptive statistics included mean and SD for normally distributed variables and median with interquartile range (IQR) for non-normally distributed variables. Categorical variables were summarized as percentages. Statistical analysis was performed using Stata version 13.0 (StataCorp, College Station, TX, USA) statistical software.

\section{Results}

One hundred eyes of 50 patients were studied. The median age at presentation was 36 months (IQR: 26, 40) without any gender predisposition (M: 26, F: 24). A predisposition to laterality was noted in $62 \%(31 / 50)$ of patients showing a right-sided involvement. All patients presented with symptoms of epiphora. Table 1 displays the ocular parameters,

Table I Ocular parameters

\begin{tabular}{lll}
\hline Parameter & Median (IQR) & Range \\
\hline LogMAR OD & $0.3(0.09,0.64)$ & $0-0.95$ \\
LogMAR OS & $0.3(0,0.64)$ & $0-0.95$ \\
SE OD & $\mathrm{I} .25(0.25,1.5)$ & -1.75 to 4 \\
SE OS & $\mathrm{I}(0.25,1.5)$ & -1.75 to 4 \\
Axial length OD & $21.24(20.65,21.79)$ & $17.92-22.89$ \\
Axial length OS & $21.20(20.6,21.76)$ & $17.9-23.8$ \\
Average keratometry OD & $43(42.13,45.2)$ & $39-49.25$ \\
Average keratometry OS & $42.7 \mathrm{I}(42.37,43.75)$ & $40.25-47.36$ \\
\hline Abbreviations: OD, oculus dexter; OS, oculus sinister; IQR, interquartile range.
\end{tabular}

Table 2 Refractive errors with amblyogenic potential

\begin{tabular}{|c|c|c|c|}
\hline \multirow{2}{*}{$\begin{array}{l}\text { Serial } \\
\text { number }\end{array}$} & \multirow{2}{*}{$\begin{array}{l}\text { Age in } \\
\text { months }\end{array}$} & \multicolumn{2}{|l|}{ Refractive error } \\
\hline & & CNLDO eye & Fellow eye \\
\hline I & 72 & +4DS/-3.75DC@10 & +2.0DS/-0.75@।80 \\
\hline 2 & 72 & +4DS/-3.75DC@।80 & +2.0DS/-0.75@।80 \\
\hline 3 & 60 & +2.5DS/-2DC@।80 & +0.75 \\
\hline 4 & 48 & +1.25DS/-2DC@40 & $-1.5 \mathrm{DS}$ \\
\hline 5 & 70 & $+3.25 \mathrm{DS}$ & $+1.25 \mathrm{DS}$ \\
\hline
\end{tabular}

Abbreviation: CNLDO, congenital nasolacrimal duct obstruction.

including visual acuity in logMAR, axial lengths and keratometry and their IQRs. Seven (14\%) of the patients were noted to have amblyopia risk factors as per the AAPOS guidelines: five (10\%) were secondary to refractive errors and two $(4 \%)$ had congenital cataracts, of which the cataract was unilateral in one and bilateral in the other. The anisometropia noted in the five patients showed the worse eye to be the one with CNLDO in all the cases. Table 2 shows the details of refractive errors. The common refractive error noted was a compound hyperopic astigmatism in three eyes followed by mixed astigmatism and simple hyperopia in one eye each.

\section{Discussion}

The current study found a marginally higher prevalence of amblyopia risk factors in patients with unilateral CNLDO as compared to those reported in general population. Hence, there is a need for a careful evaluation of these factors in children with CNLDO that would facilitate their early diagnosis and appropriate treatment.

Literature is divided on the question of association of amblyopia risk factors with CNLDO. Matta et al ${ }^{5}$ studied 402 patients with CNLDO and found the prevalence of amblyopia risk factors in $22 \%(n=88)$ of them. The risk factors in $74 \%$ of them $(n=65)$ were ascribed to refractive errors, in $10 \%(n=9)$ to strabismus and in $16 \%(n=14)$ to the combination of both. Piotrowski et $\mathrm{al}^{6}$ studied 305 consecutive children with CNLDO and showed 9.8\% $(n=33)$ of them to have anisometropia. However, anisometropia with amblyopia was noted in $5.2 \%(n=16)$ of the cohort. The most common refractive error was hyperopic anisometropia, seen in $86.6 \%(26 / 30)$, and of these, $88.5 \%(23 / 26)$ had severe hyperopia in the eyes with CNLDO. Eshraghi et $\mathrm{al}^{7}$ studied 433 cases of CNLDO and reported amblyopia risk factors in $9.5 \%(n=41)$; of these, $58.5 \%(n=24)$ were secondary to anisometropia. The authors found that the refractive error was higher in the CNLDO eyes as compared to the fellow eye $(p<0.001)$. Ramkumar et $\mathrm{al}^{8}$ studied 142 children with CNLDO and reported the prevalence of amblyopia risk 
factors in 20\% $(n=28)$. Similarly, Ozgur et $\mathrm{al}^{9}$ reported amblyopia risk factors in $27.5 \%(n=14)$ among their cohort of 51 patients, and $\mathrm{Kim}$ et $\mathrm{al}^{10}$ reported the risk factors in $35 \%(n=9)$ among their cohort of 26 patients. Siddiqui et al ${ }^{11}$ studied 161 patients of CNLDO and reported a statistically significant higher incidence of refractive errors in patients with unilateral CNLDO as compared to bilateral cases. In comparison, the current study focused only on unilateral cases and compared the amblyogenic risk factors between the eye with CNLDO and its fellow eye without CNLDO. The prevalence of amblyopia risk factors was marginally high in the current cohort as compared to the reports from general population. Similar to Piotrowski et al, ${ }^{6}$ the current study showed hyperopic astigmatism to be the most common and the CNLDO eye to have a higher refractive error as compared to the fellow eye.

Contrary opinions also exist in the literature. Ellis et $\mathrm{al}^{12}$ studied a large cohort of 4,792 children and found documented visual acuity in 2,249 patients. There was no statistically significant difference in the incidence of amblyopia between CNLDO cases and controls $(p<0.89)$. There was neither a significant correlation between refractive errors and CNLDO $(p<0.26)$ nor was there such a correlation with astigmatism $(p<0.32)$ and strabismus $(p<0.89)$. They concluded that allowing spontaneous resolution of CNLDO would not affect visual maturation. Pyi Son et al ${ }^{13}$ studied 244 cases of CNLDO and noted that cases which showed early spontaneous resolution had a higher chance of anisometropia as compared to those with late spontaneous resolution or the ones requiring a surgical intervention.

Limitations of the current study include smaller sample size and exclusion of bilateral cases of CNLDO. Strengths of the study include uniform protocols, examination under anesthesia by the same ophthalmologist and optometrist and studying the fellow eye of unilateral CNLDO as internal controls for comparison.

In conclusion, the definite establishment of a correlation between CNLDO and amblyopia risk factors requires large multicentric studies. The overall literature supports such association, and hence, a comprehensive evaluation including a cycloplegic refraction is desirable in all patients with CNLDO.

\section{Disclosure}

Mohammad Javed Ali received support from the Alexander von Humboldt Foundation for his research and also receives royalties from Springer for the textbook "Principles and Practice of Lacrimal Surgery" and treatise "Atlas of Lacrimal Drainage Disorders". The other authors declare no conflicts of interest in this work.

\section{References}

1. Geurry D, Kendig EL. Congenital impatency of the nasolacrimal duct Arch Ophthalmol. 1948;39:193-204.

2. Kamal S, Ali MJ, Gauba V. Congenital nasolacrimal duct obstruction. In: Ali MJ, editors. Principles and Practice of Lacrimal Surgery. 2nd ed. Singapore: Springer; 2018:117-132.

3. Macewen CJ, Young JDH. Epiphora during the first year of life. Eye. 1991;5:596-600.

4. Simons K. Amblyopia characterization, treatment, and prophylaxis. Surv Ophthalmol. 2005;50:123-166.

5. Matta NS, Singman EL, Silbert DI. Prevalence of amblyopia risk factors in congenital nasolacrimal duct obstruction. $J$ AAPOS. 2010; 14:386-388.

6. Piotrowski JT, Diehl NN, Mohney BG. Neonatal dacryostenosis as a risk factor for anisometropia. Arch Ophthalmol. 2010;128:1166-1169.

7. Eshraghi B, Akbari MR, Fard MA, et al. The prevalence of amblyogenic factors in children with persistent congenital nasolacrimal duct obstruction. Graefes Arch Clin Exp Ophthalmol. 2014;252:1847-1852.

8. Ramkumar VA, Agarkar S, Mukherjee B. Nasolacrimal duct obstruction: does it really increase the risk of amblyopia in children? Indian $J$ Ophthalmol. 2016;64:496-499.

9. Ozgur OR, Sayman IB, Oral Y, Akmaz B. Prevalence of amblyopia in children undergoing nasolacrimal duct irrigation and probing. Indian J Ophthalmol. 2013;61:698-700.

10. Kim JW, Lee H, Chang M, et al. Amblyopia risk factors in infants with congenital nasolacrimal duct obstruction. J Craniofac Surg. 2013;24: $1123-1125$.

11. Siddiqui SN, Mansoor H, Asif M, et al. Comparison of anisometropia and refractive status in children with unilateral and bilateral congenital nasolacrimal duct obstruction. $J$ Pediatr Ophthalmol Strabismus. 2016;53:168-172.

12. Ellis JD, MacEwen CJ, Young JD. Can congenital nasolacrimal-duct obstruction interfere with visual development? A cohort case control study. J Pediatr Ophthalmol Strabismus. 1998;35:81-85.

13. Pyi Son MK, Hodge DO, Mohney BG. Timing of congenital dacryostenosis resolution and the development of anisometropia. $\mathrm{Br} \mathrm{J}$ Ophthalmol. 2014;98:1112-1115.

14. Donahue SP, Arnold RW, Ruben JB. Preschool vision screening: what should we be detecting and how should we report it? Uniform guidelines for reporting results of preschool vision screening studies. J AAPOS. $2003 ; 7: 314-316$.
Clinical Ophthalmology

\section{Publish your work in this journal}

Clinical Ophthalmology is an international, peer-reviewed journal covering all subspecialties within ophthalmology. Key topics include: Optometry; Visual science; Pharmacology and drug therapy in eye diseases; Basic Sciences; Primary and Secondary eye care; Patient Safety and Quality of Care Improvements. This journal is indexed on Submit your manuscript here: http://www.dovepress.com/clinical-ophthalmology-journal

\section{Dovepress}

PubMed Central and CAS, and is the official journal of The Society of Clinical Ophthalmology (SCO). The manuscript management system is completely online and includes a very quick and fair peer-review system, which is all easy to use. Visit http://www.dovepress.com/ testimonials.php to read real quotes from published authors. 